Linha D'Água (Online), São Paulo, v. 29, n. 1, p. 45-66, jun. 2016

\title{
A CANTIGA MEDIEVAL COMO MEMÓRIA HISTÓRICA DA CONSTRUCAÃO SOCIAL DO GÊNERO FEMININO: REFLEXÕES PARA O ENSINO DE LITERATURA
}

\author{
THE MEDIEVAL SONG AS HISTORICAL MEMORY OF THE SOCIAL \\ CONSTRUCTION OF FEMALE: REFLECTIONS FOR LITERATURE TEACHING
}

\author{
Micheline Mattedi Tomazi* e Paulo Roberto Sodrét* \\ Universidade Federal do Espírito Santo, Vitória, ES, Brasil
}

\begin{abstract}
Resumo: Este artigo tem como objetivo demonstrar como a representação social da mulher foi construída historicamente para a consolidação de uma memória social estereotipada, sexista e patriarcal do gênero feminino na sociedade ocidental cristã e como, a partir de uma perspectiva multidisciplinar e crítica, com aporte teórico da proposta sociocognitiva dos Estudos Críticos do Discurso e da Crítica Literária, é possivel propor discussões para essa questão no ensino do texto literário medieval e recuperar o diálogo com questões sociais que, ainda hoje, representam motivo de preocupação para nossa sociedade. A partir do estudo de uma cantiga medieval de Afonso X (século XIII), procuramos apresentar as estratégias discursivas que revelam a construção polarizada da representação social medieval de um grupo duplamente minoritário: a mulher (gênero) e a soldadeira (atividade profissional). Os resultados deste artigo, ao delinear as formas pelas quais alguns conceitos produzidos nos Estudos Críticos do Discurso podem contribuir para uma consciência dialógica do aluno no ensino do texto literário, apontam para a necessidade de se considerar questões sociais no ensino, que não só propiciem aos alunos a percepç̃õo das relações dialógicas entre épocas distintas, mas também recuperem a discussão de uma memória histórica, cultural e social sobre o tema da mulher.
\end{abstract}

Palavras-chave: Estudos críticos do discurso; Crítica literária e ensino de literatura; Sátira medieval galego-portuguesa e ensino de literatura; Memória histórica e social de gênero..

\begin{abstract}
This article aims to demonstrate how the social representation of women was historically built to consolidate a stereotypical social memory, sexist and patriarchal female in Christian Eastern society and from a multidisciplinary perspective and critical with theoretical support of sociocognitive proposal of Critical Studies of Speech and literature critics, it is possible to propose discussions on this issue in the medieval literary text teaching and recover the dialogue with social issues that today represent a concern for our society. From the study of a medieval song from Alfonso X (XIII century), we try to present the discursive strategies that reveal the polarized construction of the medieval social representation of a double minority: a woman (gender) and "soldadeira" (occupation). The results of this article to outline the ways in which some concepts produced in the Speech from the Critical Studies can contribute to a dialogical awareness of the student in literary text teaching, point to the need to consider social issues in education, which not only conducive to students perception of the dialogical relations between different times, but also recover the discussion of a historical memory, cultural and social on the subject of women.
\end{abstract}

Keywords: Critical Discourse Studies; Literary Critics and Literature Teaching; Galician-Portuguese Medieval Satire and Literature Teaching; Historical and Social Memory of Gender.

* Professora doutora da Universidade Federal do Espírito Santo - UFES, Vitória, ES, Brasil; michelinetomazi@gmail.com

** Professor doutor da Universidade Federal do Espírito Santo - UFES, Vitória, ES, Brasil; paulorsodre8@gmail.com 
Linha D'Água (Online), São Paulo, v. 29, n. 1, p. 45-66, jun. 2016

\section{Introdução}

Muitos pesquisadores de diferentes áreas procuram observar e discutir quais ideologias favorecem o poder e a hegemonia da figura masculina na sociedade, ao mesmo tempo em que buscam delinear um retrato cultural da mulher que, ao longo dos séculos, sempre teve sua identidade construída em função do elemento masculino. Nesse sentido, a questão de gênero social envolve uma visão binária que tem registros históricos baseados culturalmente na imagem de figuras distintas de gênero e de papeis sociais: feminino e masculino. Aspectos ideológicos, próprios de uma sociedade patriarcal, contribuem para a construção dessa hegemonia, caracterizando uma memória do gênero social feminino ligada a aspectos de submissão e dominação masculina que foi construída ao longo da história e questionada com os movimentos feministas, a partir da década de 1960, cujo objetivo foi garantir direitos iguais entre os gêneros.

Segundo Dias (2013, p. 121), "o movimento feminista surgiu como uma linha radical que questionava valores ideológicos da sociedade em relação ao gênero social" e hoje, o movimento pós-feminista acredita que as relações de gênero podem ser igualitárias, mas valoriza "as diferenças entre os gêneros que não podem ser negadas, nem serem vistas como oposições em que uma identidade só exista em função da outra”.

Assim, fica claro que a questão que envolve a diferença de gêneros sociais possui uma dimensão que vai além da história, já que, além de passar pelas práticas sociais e discursivas, guarda uma memória porque incorpora ideias, pensamentos, crenças e valores. É nesse sentido que o tema desta edição da revista nos instigou a escrever este artigo. Acreditamos que resgatar uma memória histórica e social de um gênero discursivo tão antigo como a cantiga medieval, que versa sobre a mulher, não é, como muitos poderiam pensar, um assunto já esgotado em termos de suscitar uma discussão em que se leve em conta o discurso e o ensino do texto literário como prática discursiva. Esse mesmo ensino do texto literário deve, entendemos, considerar a sociedade na qual os textos são produzidos, bem como a representação de grupos sociais e das cognições sociais dos participantes desses grupos.

Pensamos a cognição como um processo mental, que serve para mediar as complexas relações entre estruturas sociais e estruturas discursivas, uma vez que ela é entendida como as crenças, os objetivos, as emoções e mesmo as avaliações que podem interferir na interação (VAN DIJK, 2010). A cognição, nessa perspectiva, guarda uma relação direta com a memória episódica (aquela que reúne as crenças fundamentadas em experiências pessoais) e a memória social (aquela que congrega as crenças e conhecimentos partilhados que passam de geração para geração). Para nós, o ensino com o texto literário, seja qual for, precisa fazer a mediação entre três 
Linha D'Água (Online), São Paulo, v. 29, n. 1, p. 45-66, jun. 2016

conceitos: discurso, sociedade e cognição. Isso porque acreditamos que a interface entre esses conceitos no ensino de literatura é uma maneira de demonstrar como nossa memória histórica, social e cultural pode afetar nossa visão ideológica sobre a maneira como entendemos e reconhecemos a imagem da figura feminina, da mulher, e a imagem da figura masculina, do homem, como participantes de relações de poder, de abuso de poder, ou mesmo de violência.

Com base nessa visão, apoiamo-nos em Castells (2006) que mostrou a relevância de se refletir sobre a reprodução de aspectos ligados ao gênero social por discursos institucionalizados. Para nós, é importante refletir sobre o fato de que é na e pela linguagem que a institucionalização discursiva de gênero chega até nós pelo discurso das elites simbólicas (VAN DIJK, 2010), ou seja, pela mídia, pelos livros didáticos, pelos professores, pelos jornalistas, enfim, por aqueles que têm acesso ao discurso público.

É por esse caminho que pretendemos pensar o ensino de literatura e as práticas de formação de um leitor crítico, capaz de reconhecer estratégias e estruturas discursivas que engendram relações de poder e dominação no texto literário independente da época em que ele foi produzido. Este artigo, portanto, percorre o objetivo de refletir sobre como um enunciador masculino representa a mulher e constrói a representação feminina na cantiga "[Maria Pérez vi muit' assanhada]" de Afonso X (século XIII), em que uma soldadeira, dançarina que acompanhava as apresentações de trovadores e jograis nas cortes peninsulares - em geral confundida com prostitutas - reclama do tratamento desrespeitoso recebido do trovador, a figura masculina de Pero d'Ambroa.

Adotamos um arcabouço teórico multidisciplinar que faz dialogarem a Crítica Literária e os Estudos Críticos do Discurso, buscando uma associação entre questões discursivas, sociais, cognitivas e o ensino de literatura.

Este artigo está organizado em quatro seções. A primeira é dedicada a uma discussão teórica sobre os estudos críticos do discurso; a segunda procurará demonstrar as ferramentas dos estudos críticos do discurso para uma leitura crítica do texto em diálogo com a crítica literária; a terceira seção apresentará a análise interpretativa da cantiga medieval; em seguida, a última seção é destinada às considerações finais, quando apresentamos algumas reflexões sobre a produção de sentidos a partir dessa perspectiva de leitura. 
Linha D'Água (Online), São Paulo, v. 29, n. 1, p. 45-66, jun. 2016

\section{Os estudos críticos do discurso: ideologia, poder e representação social de gênero}

Os estudos críticos do discurso têm particular interesse pela investigação de questões que envolvem problemas sociais, relações de poder e dominação, de modo geral, e em especial, pelo papel do discurso e pelo uso linguístico. Por isso, o discurso é visto como uma prática social que está intimamente ligada a essas questões, uma vez que ele está envolvido em condições de produção que nos permitem reconhecer os elementos que, na e pela linguagem, são discursivamente acionados para a dominação e a manipulação. É o caráter social dessa análise do discurso que possibilita ao pesquisador engajar-se criticamente na análise de textos que, de alguma forma, revelam a construção da representação social de um grupo na sociedade, em diferentes épocas, como o discurso sexista, o discurso homofóbico, o discurso racista, entre outros.

Esses estudos críticos do discurso tomam, então, como objeto de pesquisa a reprodução discursiva de abuso de poder e de desigualdade social, entendendo o texto como unidade mínima de análise. $\mathrm{Na}$ proposta dos estudos críticos de van Dijk (2010, 2012), a relação entre a estrutura social e a estrutura discursiva não é direta, é mediada pela cognição pessoal e social, por isso a importância de se estabelecerem relações fundamentais entre um triângulo de conceitos, a saber: o discurso, a cognição e a sociedade. Essa tríade permite pensar não só a dimensão linguística do discurso, mas a cognitiva, a social, a política, a cultural e a histórica. Assim, o controle do discurso passa pelo contexto, pela linguagem, pela identidade, pela ideologia e pelos objetivos argumentativos.

A concepção de ideologia proposta por van Dijk $(1998,2010)$ entende que ela é uma estrutura cognitiva complexa que controla a formação, a transformação e a aplicação de outros tipos de cognição social, tais como o conhecimento, as opiniões e as posturas, e de representações sociais, como os preconceitos sociais. Essa estrutura ideológica consiste em normas, valores, metas e princípios socialmente relevantes que são selecionados, combinados e aplicados de maneira que possam oferecer à percepção, e à interpretação das práticas sociais que beneficiam os interesses do grupo tomado como um todo (VAN DIJK, 2010, p. 43).

Todas as ações discursivas praticadas na sociedade por cidadãos ou por seus representantes são mediadas pelas ideologias dos grupos, sejam eles dominantes, sejam dominados, tendo em vista que "uma ideologia proporciona coerência às atitudes sociais, que por sua vez, codeterminam as práticas sociais" (VAN DIJK, 2010, p. 43). Portanto, todos os discursos proferidos pelos falantes, direta ou indiretamente, estão inevitavelmente ligados às ideologias do grupo ao qual pertencem. 
Linha D'Água (Online), São Paulo, v. 29, n. 1, p. 45-66, jun. 2016

Pensar nas relações sociais e, logo, nos posicionamentos ideológicos que norteiam as práticas discursivas dos sujeitos é, sem dúvida, pensar nas relações de poder e hegemonia. Sabemos que na sociedade as pessoas ocupam posições sociais diferentes, portanto o que se observa é que "o poder é exercido e expresso diretamente por meio do acesso diferenciado aos vários gêneros, conteúdos e estilos de discurso" (VAN DIJK, 2010, p. 44). O sentido de poder que tomamos como base encontra respaldo no conceito proposto por van Dijk (2010), que o entende como controle que um grupo exerce sobre outros grupos e seus membros. Esse poder é simbólico porque é capaz de manipular, persuadir, seduzir, doutrinar pessoas e se perpetuar como senso comum na sociedade.

Para o autor, as representações sociais são os conhecimentos socioculturais, elaborados e compartilhados socialmente, que nos permitem agir, interagir e comunicar de forma significativa com outros membros da mesma cultura. Ele ainda atribui, a essa noção de representação social, o caráter cognitivo, uma vez que, se a manipulação discursiva é capaz de controlar as representações sociais compartilhadas, então, a manipulação se centrará na cognição social, ou seja, influenciará na formação e ativação das crenças que possuímos em relação a um determinado grupo, pois os preconceitos são representações sociais negativas estereotipadas, já os argumentos em si podem ser estereotipados e convencionais (VAN DIJK, 2010, p. 143).

Desse modo, podemos dizer que o discurso ideológico é uma forma simbólica veiculada discursivamente no texto que atua na transmissão e manutenção da "hegemonia",já que hegemonia, segundo Gramsci (1971), corresponde à liderança cultural e ideológica de um grupo sobre os demais. Podemos observar que o sexismo e o racismo são exemplos de hegemonia que podem ser exercidos por meio de atos abusivos ou somente incorporados em ações cotidianas que se tornam normais e passam a fazer parte de nossa vivência em sociedade ou de nossa memória social, isto é, de nossos conhecimentos compartilhados.

Nesse sentido, entendemos que é possível um diálogo da teoria multidisciplinar e de base sociocognitiva proposta por van Dijk $(2010,2012)$ para a análise da representação social da mulher na Idade Média, tomando como objeto de análise a cantiga trovadoresca à luz do momento histórico-literário que queremos enfatizar. Isso porque, se as ideologias são adquiridas, expressadas e reproduzidas pelo discurso é, então, no discurso que podemos identificar as estratégias e estruturas discursivas utilizadas como um recurso para disseminar a ideologia dominante. Segundo van Dijk (2010), a análise detalhada dos discursos permite-nos compreender que eles são basicamente ideológicos, por isso, as manipulações sociais e políticas sempre envolverão ideologias, atitudes ideológicas e estruturas ideológicas de discurso. Seria, portanto, incoerente para um ensino crítico da literatura, 
Linha D'Água (Online), São Paulo, v. 29, n. 1, p. 45-66, jun. 2016

propor a análise de um texto, no caso em apreço, a análise de uma cantiga, sem considerar toda a riqueza interpretativa e ideológica da construção social de gênero que já na Idade Média é construída e que resvala - ou dura, como defende a Nova História -, ainda hoje, em nossa sociedade.

Ora, se a literatura tem uma função social, é no ensino que o professor tem a liberdade de demonstrar como o discurso é controlado e como esse controle afeta a sociedade. O discurso, como prática social, é contextualizado e o texto é o lugar propício para o reconhecimento da materialidade discursiva. Uma vez que quem controla o discurso controla o poder e os efeitos do discurso sobre a sociedade, precisamos reconhecer que o discurso é texto contextualizado e, portanto, o texto é o resultado de estratégias utilizadas para enfatizar os interesses dos grupos dominantes.

É importante considerar que, se o discurso se materializa nos textos, é porque o uso da língua, em textos orais ou escritos, não pode ser apenas considerado em sua função de entretenimento, no caso do texto literário, mas na sua dimensão constitutiva de discurso ideológico, como, já na década de 1920, adiantou Bakhtin (1999).

Nessa perspectiva, as estruturas discursivas se dão em vários níveis porque estabelecem o quadrado ideológico de polarização de um grupo. A estratégia de polarização discursiva é encontrada em todos os discursos ideológicos, segundo a concepção de van Dijk (2010,2012). O pesquisador assinala que a polarização é uma estratégia geral envolvida na reprodução discursiva de dominação que pode ser realizada em várias formas e níveis de discurso. Trata-se de dar ênfase às coisas boas em Nós e ruins nos Outros. Desse modo, podemos dizer que o discurso ideológico é geralmente organizado por uma estratégia global de autoapresentação positiva (Nós) e de outroapresentação negativa (Eles). Vejamos, abaixo, a proposta desse "quadrado ideológico":

\section{Enfatizar aspectos positivos sobre Nós \\ Enfatizar aspectos negativos sobre Eles \\ (Des)enfatizar aspectos negativos sobre Nós \\ (Des)enfatizar aspectos positivos sobre Eles}

Quadro 1: Quadrado ideológico de polarização com base em Van Dijk (2010, p. 137).

Pela observação do quadro acima, percebemos que o reforço dos atributos negativos ou positivos é feito pelo uso de estratégias discursivas. Ou seja, por meio de uma escolha lexical, por exemplo, podemos reforçar características negativas nos Outros e positivas em Nós.

Além disso, podemos ainda encontrar o que o autor denomina como disclaimers (ressalvas) que reforçam o positivo sobre Nós e o negativo sobre Eles. 
Linha D'Água (Online), São Paulo, v. 29, n. 1, p. 45-66, jun. 2016

Van Dijk (2010, p. 142) elenca os seguintes tipos de disclaimers: negação aparente; concessão aparente; empatia aparente; ignorância aparente; desculpa aparente; inversão de culpa e transferência.

Os disclaimers são movimentos semânticos que materializam dentro de uma oração as estratégias de autoapresentação positiva e outroapresentação negativa. Dito de outra forma, estes dispositivos reforçam o posicionamento de determinados grupos dentro do discurso. Diante desse ponto de vista, se não se pode negar a importância da noção de discurso como prática social, também não se pode desconsiderar o fato de que o texto é a manifestação de um discurso e, sendo assim, discurso e texto, como produtos da enunciação, determinam a forma de adquirir, aprender, apreender e modificar as ideologias.

Nessa perspectiva é que leremos o texto selecionado para análise neste artigo, uma cantiga satírica de Afonso X, o Sábio (1221-1284), que empresta voz a uma mulher soldadeira na época do Trovadorismo. A imagem feminina em um período histórico no qual ela é vista duplamente como minoria (SCHMITT, 1998; FILIOS, 1998; LANZ, 2002; ZAREMSKA, 2002) - mulher e prostituta - nos permite não só estudar a representação social dessa minoria, construída no e pelo discurso do trovador, mas também refletir - em especial no âmbito do ensino - sobre a atuação de um discurso que traz à memória uma visão estereotipada, patriarcal, sexista da literatura em particular, e de seu efeito ainda profícuo nas relações assimétricas de poder em nossa sociedade.

É, pois, em diálogo com essas reflexões que defendemos, neste artigo, um ensino do texto literário como uma ferramenta poderosa para discutir temas que persistem em nossa memória compartilhada e em nossa sociedade sobre a maneira como foi construída a representação social da mulher em contextos históricos distintos, mas que podem durar longamente em seu próprio tempo e até os dias atuais. Isso posto, teceremos algumas reflexões sobre a proposta de diálogo entre as áreas para um ensino crítico.

\section{Por um ensino crítico da cantiga medieval}

Para Baynham (1995) é imprescindível que o ensino esteja voltado, em qualquer área do conhecimento, para situações críticas ou problematizadoras que são materializadas na e pela linguagem como prática social. Muitos autores já se preocuparam com essa visão mais crítica, entre eles podemos citar, além de Baynham (1995), Meurer (2000), Oliveira (2012), Heberle e Meurer (1993), Heberle (2000), entre outros.

Para Meurer (2000), o ensino crítico de um texto implica em procurar entender que representar o mundo de uma determinada maneira, construir e interpretar 
Linha D'Água (Online), São Paulo, v. 29, n. 1, p. 45-66, jun. 2016

textos evidenciando determinadas relações e identidades constituem formas de ideologia, já que ideologia, para o autor, perpassa todas as nossas práticas discursivas e sociais e está implícita nas formas de ver, pensar, compreender, desafiar ou, acrescentamos, recriar o mundo a partir da literatura. Por isso, é preciso que se veja o processo de ensino do texto literário em geral e da literária em particular na sua abrangência social e não apenas na sua dimensão cognitiva e estética.

Toda essa digressão é pressuposto para que se compreenda que é preciso que o ensino se volte para uma perspectiva social crítica na qual o leitor não só possa contestar, mas "quebrar o círculo do senso comum, daquilo que parece natural, não problemático, mas que recria e reforça formas de desigualdade e discriminação" (MEURER, 2000, p. 169).

Em diálogo com van Dijk (2001a), Meurer (2000) reconhece que uma abordagem crítica da leitura no ensino "implica estabelecer conexões de forma a perceber que os textos constituem, reconstituem e/ou alteram práticas discursivas e sociais". Nesse sentido, produzir um ensino crítico de textos é reconhecer que os textos refletem, promovem, recriam ou desafiam a estrutura social; muitas vezes, contestam ou corroboram essa estrutura desigual, discriminatória ou mesmo abusiva.

Isso significa que os textos não apenas criam representações que refletem, constroem e/ou desafiam nossos conhecimentos ou crenças, mas também cooperam para que possamos estabelecer relações sociais, recuperar nossa memória histórica e construir nossa própria identidade (MEURER, 2000). Ao propor um ensino de leitura crítica que desnaturalize os discursos naturalizados que veiculam ideologias capazes de produzir e reproduzir relações desiguais de poder, na medida em que reforçam preconceitos, a vertente crítica de análise do discurso, de van Dijk (2001a, 2001b, 2010, 2012), dialoga com a proposta de Meurer (2000) porque entende que todo discurso é controlado pelo contexto, por isso sua teoria pode ser aplicada em qualquer texto, de qualquer época, já que um discurso pode ser retomado em diferentes épocas e em diferentes esferas comunicativas, sobretudo, se considerarmos o que se conhece, na História das Mentalidades, como "longa duração". O que vai determinar o seu novo sentido são os aspectos contextuais, as instituições, a classe social, as ideologias etc.

Van Dijk (2001b) propõe uma noção de contexto a partir da interface entre as estruturas de situações sociais e as formas como os atores sociais representam mentalmente essas situações, buscando compreender como essas representações podem influenciar na produção e compreensão do discurso. Assim, a teoria do contexto explica como os participantes são capazes de adaptar a produção, recepção e interpretação do discurso à situação de comunicação social. Nesse sentido, 
Linha D'Água (Online), São Paulo, v. 29, n. 1, p. 45-66, jun. 2016

não é a situação social comunicativa que influencia na construção das estruturas discursivas, mas a representação mental de cada participante.

Van Dijk (2012) apresenta o conceito teórico de que contextos são construtos subjetivos dos participantes, ou definições subjetivas das situações interacionais ou comunicativas. Desse modo, os contextos são experiências únicas, nos quais aparecem as experiências vividas pelo corpo, percepções, emoções, referentes à situação comunicativa em curso. Assim como os contextos são únicos, as formas de se utilizar a linguagem também o são, por isso os discursos são únicos. Van Dijk (2012) expõe ainda que os construtos dos participantes, subjetivos, embora socialmente fundamentados, são construídos a respeito das propriedades que para eles são relevantes em tal situação, isto é, modelos mentais. Desse modo, os indivíduos não estão apenas envolvidos em processar um discurso, mas engajados em construir dinamicamente sua análise e interpretação subjetiva on-line (VAN DIJK, 2012).

Além da representação do sentido de um texto, os usuários de uma língua constroem modelos mentais dos eventos que são assunto desses textos, isto é, a situação que eles têm como denotação ou referência. Por isso, os modelos mentais são representações cognitivas de nossas experiências e possuem, segundo van Dijk (2001), categorias contextuais gerais como: cenário (tempo, lugar), participantes e um evento ou ação. A marca de tais categorias no discurso pode ser identificada pelas descrições indexicais (VAN DIJK, 2010).

A diferença entre situação social e contexto é que contexto não é algo externo, fora dos participantes, mas sim algo construído por eles a partir de um modelo mental específico chamado de modelo de contexto ou apenas contexto. Segundo van Dijk (2001), como todos os modelos mentais, o modelo de contexto não representa todos os aspectos pessoais ou sociais da situação comunicativa, mas apenas os aspectos que em um dado momento são relevantes para cada participante. Logo, as estruturas discursivas serão limitadas pelas categorias da situação comunicativa como a situação corrente (hora, localização), circunstâncias correntes (o que está sendo discutido), os vários papeis dos participantes etc.

No caso da produção trovadoresca de cantigas de escárnio e maldizer, esse aspecto é um dos que mais desafiam os críticos, haja vista a série de alusões a situações desconhecidas que estrutura o contexto das cantigas, tornando-as, não poucas vezes, ilegíveis. Felizmente, muitas delas conseguem autonomia contextual, favorecendo a compreensão do leitor, como a cantiga sobre a reação de uma soldadeira à zombaria de Pero d'Ambroa, em que se percebe um suposto tipo de recepção do escárnio e maldizer realizada, por exemplo, pelas mulheres. Entretanto, se, ao apresentar o texto para os alunos, nós, como professores, representantes de uma elite simbólica, não discutirmos ou recuperarmos os modelos de contexto daquela 
Linha D'Água (Online), São Paulo, v. 29, n. 1, p. 45-66, jun. 2016

época e como eles ainda persistem na nossa sociedade quando o tema é a figura feminina, a leitura resultaria anódina.

Assim, entendemos que a teoria do contexto ajuda a entender como as estruturas sociocognitivas de uma situação de comunicação se relacionam com as estruturas do discurso desse evento. Isso implica compreender a questão do poder e da ideologia a que subjazem os discursos e, principalmente, implica adotar um conceito de ensino para interpretação e leitura de textos como prática social.

Nessa abordagem é que a mulher enfezada, devido ao escárnio de um trovador, referida pelo Rei Sábio de Leão e Castela, Afonso X, ganha relevo: observar numa cantiga produzida na e para a corte do século XIII peninsular - berço complexo de nossa cultura colonial - os distintos discursos e ideologias a durarem até nossos dias enseja um exercício fecundo de percepção crítica do discurso, seja do ponto de vista da história da cultura, da literatura, seja da história social, da mulher.

Diante dessas considerações, passamos à análise propriamente dita da cantiga.

\section{As peras da soldadeira: memória crítica da construção social de gênero e da polarização na cantiga medieval}

Dentre as centenas de cantigas trovadorescas galego-portuguesas que nos foram transmitidas pelos cancioneiros quinhentistas italianos, Cancioneiro da Biblioteca Nacional (CBN) e Cancioneiro da Vaticana (CV), algumas nos chegaram incompletas, desafiando os editores a conjeturarem palavras, versos e estrofes (principalmente refrãos). Desses casos é exemplo a cantiga CBN [471'] (LAPA, 1995, 1, p. 21; PAREDES, 2010, XVI, p. 146-147), de Afonso X. Os editores desafiados foram Carolina Michaëlis de Vasconcelos (2004, p. 236; p. 264) e Manuel Rodrigues Lapa, que deduziram ser de Maria Pérez a voz da cantiga afonsina: "Quase toda a cantiga é posta na boca duma mulher, que, supomos ser a célebre Maria Balteira; com efeito, faz-se alusão aos cantares, em que Pero d'Ambroa a achincalha fortemente (n. 331, 337)" (LAPA, [1965] 1995, p. 21).

Carlos Alvar (1985, p. 20-21), no entanto, desconsidera essa referência na cantiga, uma vez que não encontrou nenhum fundamento para a suposição dos filólogos. Segundo Alvar (1985), Carolina Michaëlis e Rodrigues Lapa supõem, como outros críticos, que no verso inicial ${ }^{1}$ seria mencionado o nome de Balteira.

1 O verso inicial da cantiga proposto por Michaëlis é "[Maria Balteira está assanhada] (2004, p. 236; p. 264); o adotado por Lapa, que contesta a solução da filóloga alemã, é "[Maria Pérez vi muit' assanhada]" (1995, p. 21), mas ambos são omitidos na edição de Juan Paredes (2010) e Mercedes Brea (2011). Lopes, no entanto, mantém a versão de Lapa (http:// www. cantigas.fcsh.unl. pt/cantiga. asp? cdcant=473\&pv=sim).

TOMAZI, M. M.; SODRÉ, P. R. A cantiga medieval como memória histórica da construçã̃o 
Linha D'Água (Online), São Paulo, v. 29, n. 1, p. 45-66, jun. 2016

Decerto resulta presumível a hipótese, como o são outras tantas conjeturas nos estudos trovadorescos, contudo a carência de fundamento requer cuidado na defesa dessa dedução, "sobretudo se tivermos em conta que no restante da composição nunca se alude a tal dama” (ALVAR, 1985, p. 17).

Nas cantigas mencionadas por Lapa, Ambroa acusa Maria Pérez Balteira de várias maleabilidades morais, como a de sedução oportunista sugerida em "Os beesteiros d' aquesta fronteira" (CBN 1574). Nesta cantiga, ela seria hábil em subtrair o que deseja dos soldados do rei na fronteira, que usavam como arma a besta; o trovador sugere na cantiga a preconceituosa malícia da mulher em lidar rapacemente com os homens. Em "O que Balteira ora quer vingar" (CBN 1597; CV 1129), Ambroa aborda a "desonra" - isto é, em termos irônicos ou equívocos, a disponibilidade lasciva - que a Balteira sofreu não apenas por ele, mas pelos reinos de Leão, Castela, Aragão, além dos mouros: "ca de todos gram desonrra colheu / no corpo, ca non en outro logar”. Desse modo, Michaëlis e Lapa teriam razão em atrelar a "queixa" de Balteira contra Ambroa na cantiga de Afonso X. Contudo, faltos do incipit da cantiga e de comprovação segura, como orientam Alvar e, mais recentemente, o editor das cantigas afonsinas, Juan Paredes (2010), seguimos a lição sem o verso conjetural daqueles:

\footnotetext{
$\cdots$,

por que lhi rogava que perdoasse

Pero d'Ambroa, que o non matasse, nen fosse contra el desmesurada.

E diss' ela: - Por Deus, non me roguedes,

ca direi-vos de min o que i entendo:

se ũa vez assanhar me fazedes,

saberedes quaes peras eu vendo.

$\mathrm{Ca}$ [me] rogades cousa desguisada, e non sei eu quen vo-lo outrogasse, de perd[o]ar quen no mal deostasse, com' el fez a min, estando en sa pousada.

$\mathrm{E}$, pois vejo que me non conhocedes, de mi atanto vos irei dizendo: se ũa vez assanhar me fazedes, [saberedes quaes peras eu vendo].
} 
Linha D'Água (Online), São Paulo, v. 29, n. 1, p. 45-66, jun. 2016

E, se m' eu quisesse seer viltada, ben acharia quen xe me viltasse; mais, se m' eu taes non escarmentasse, cedo meu preito non seeria nada. E en sa prol nunca me vós faledes, ca, se eu soubesse, morrer' ardendo; se ũa vez assanhar me fazedes, [saberedes quaes peras eu vendo].

E por esto é grande a mia nomeada, ca non foi tal que, se migo falhasse, que en eu mui ben non-[no] castigasse, ca sempre fui temuda e dultada.

E rogo-vos que me non afiquedes daquesto, mais ide-m' assi sofrendo; se ũa vez assanhar me fazedes, saberedes quaes peras eu vendo $\left(\mathrm{CBN}\left[471^{\prime}\right]\right)^{2}$ (PAREDES, 2010, p. 146).

Descartado o verso que indicaria e dirigiria sua recepção à identificação e compreensão da específica representação da mulher - haja vista que Balteira é considerada, em geral, como soldadeira na tradição satírica galego-portuguesa -, resta-nos observar que discurso essa voz enfezada nos revela no contexto ambíguo das cantigas de escárnio e maldizer galego-portuguesas produzidas por homens da elite peninsular. Isso porque a leitura dessa produção satírica nos coloca ora diante

2 Em versão parafrástica, expomos a cantiga, cotejando leituras de Lapa (1995), Paredes (2010) e de Lopes (2013): [...] porque the rogava que perdoasse a Pero d'Ambroa, que não o matasse nem fosse excessiva contra ele. E disse ela: - Por Deus, não mo rogueis, pois vos direi o que entendo disso: se me enfezares uma vez, sabereis do que sou capaz. Porque me rogais coisa disparatada, não sei quem vos outorgasse perdoar a quem o escarnecesse tal como ele fez contra mim, estando em sua casa. $E$, pois vejo que me não conheceis, um tanto vos direi de mim: se me enfezares uma vez, sabereis do que sou capaz. E se eu quisesse ser aviltada, bem acharia quem o fizesse; mas, se eu não castigasse esses tais, cedo meu caso seria nada. Assim, nunca me faleis em seu proveito, porque se eu soubesse como daná-lo, ele morreria na fogueira [...]. Por isso minha fama é grande, pois não houve tal que, faltando comigo, não o castigasse muito bem, pelo que sempre fui temida e receada. E rogo-vos que não me afligis com isso, mas suportais-me assim [...].

TOMAZI, M. M.; SODRÉ, P. R. A cantiga medieval como memória histórica da construção 
Linha D'Água (Online), São Paulo, v. 29, n. 1, p. 45-66, jun. 2016

de um propósito lúdico de entretenimento cortesão (MADERO, 1992, p. 38), ora nos indica um objetivo denunciador das imperfeições morais e sociais, apontando as tensões da época (LIU, 2004), o que nos permite ler o conjunto satírico peninsular como documento memorial a projetar situações históricas e como monumento a revelar a competência poética, retórica e eminentemente ficcional dos trovadores (SODRÉ, 2013).

Nas cantigas de escárnio e maldizer sobre mulheres - e o grupo é relativamente extenso, como informa Graça Videira Lopes (1998, p. 236) - predomina as que são atribuídas a soldadeiras. Talvez por essa razão, ainda que diversas mulheres (abadessas, amas, viúvas, donas, vilãs, coteifas, cafetinas et al.) pudessem assumi-la, a voz da cantiga de Afonso $\mathrm{X}$ é normalmente relacionada à soldadeira, mulher que cantava, dançava e "transava" a soldo, isto é, mediante pagamento.

Como procuramos demonstrar, a representação feminina medieval a que as cantigas satíricas poderiam se referir é complexo e variado:

coser, fiar, cozinhar, lavar, cuidar da criação e esconjurar bruxedos compõem o rol das qualidades da casada [...]. Dados sobre o cotidiano feminino se detectam também na leitura das leis, em que se percebem os locais de movimento e importância da mulher: a casa, o moinho, o forno, as fontes. Os serviços das mulheres compreendem também cuidar das enfermidades e lavar roupa.

Além da educação das filhas e dos afazeres da casa, as cantigas satíricas aludem a outros aspectos do comportamento da madre. Tratando-se de um discurso maledicente, voltado para as mazelas sociais e morais, tais cantigas denunciam também o desejo fora da norma, que a madre poderia experimentar. $\mathrm{O}$ desejo de uma viúva por homem jovem e robusto é tratado na cantiga de Afonso Soárez Sança: "Poren Tareija Lópiz non quer Pero Marinho:/ pero x’el é mancebo, quer -x' ela mais meninho". Também o incesto é insinuado por Estêvão da Guarda, na cantiga "En tal perfia qual eu nunca vi", em que Don Foan diz que "Sempr' esto ["perfiar"] ouvemos d' uso,/ eu e mia madre, en nosso solaz:/ de perfiarmos eno que nos praz”. (SODRÉ, 2008, p. 65-66)

A despeito dessa variedade de papeis e atuações, as cantigas de escárnio e maldizer peninsulares destacam, como vimos, a figura da soldadeira. Trabalhos como os de Denise Filios (1998) ou Eukene Lacarra Lanz (2002) apontam e questionam o fato de as soldadeiras serem convencionalmente tomadas por lascivas e prostitutas, sem referências a suas atividades de bailarina e cantora, aliás, previstas nos códigos jurídicos da época. Entendemos que tais considerações assumem 
Linha D'Água (Online), São Paulo, v. 29, n. 1, p. 45-66, jun. 2016

extrema importância para que se compreenda a representação social que é feita da mulher, soldadeira, nas cantigas.

A voz da mulher deostada e caluniada na cantiga de Afonso X ("e non sei eu quen vo-lo outrogasse, / de perdoar quen no mal deostasse, / com' el fez a min, estando en sa pousada"), indica a situação de injúria sofrida por ela, neste caso, ocorrida fora da corte ("estando en sa pousada"). Segundo a cantiga do Rei, Ambroa ofendeu a mulher, angariando sua inimizade e uma ameaça de morte. $\mathrm{O}$ trovador - persona satírica do soberano - intercede pelo parceiro, rogando à vítima perdão pelo deosto ("por que lhi rogava que perdoasse / Pero d'Ambroa, que o non matasse, / nen fosse contra el desmesurada"). A caluniada se mostra irredutível, alegando que se agisse de modo ameno ela seria caluniada por outros, prejudicando seu prestígio ("E, se m' eu quisesse seer viltada, / ben acharia quen xe me viltasse; / mais, se m' eu taes non escarmentasse, / cedo meu preito non seeria nada”).

O refrão chama a atenção, ao expor um provérbio: "saberedes quaes peras eu vendo". Sugestiva, a imagem da pera tem suscitado leituras diferenciadas: pelo formato, os estudiosos supõem uma alusão aos seios da mulher; pelo som, um parônimo de Pero (d'Ambroa). Para a perspectiva de leitura que adotamos, satisfaznos o sentido geral da sentença: "tome cuidado comigo" (LAPA, 1995, p. 21-22).

Afonso X cria uma cantiga em que joga (SODRÉ, 2010, 2012) com a reação da presumível soldadeira, colocando em sua voz ao mesmo tempo sua fragilidade (já que se encontra à mercê dos maledicentes: "ben acharia quen xe me viltasse") e a necessidade de se proteger por meio da ameaça contra o trovador inconveniente, a exemplo do que faz com outros ("ca sempre fui temuda e dultada"). Tal montagem do discurso nos permite deduzir a facilidade da calúnia e o cuidado da mulher com sua nomeada, seja qual for sua atuação cultural e social no contexto que, infelizmente, não é detalhado, mas pode ser deduzido se tivermos como de soldadeira a voz feminina criada por Afonso X.

Assim, a cantiga expõe a voz de uma mulher defensiva e ameaçadora ("se ũa vez assanhar me fazedes, / saberedes quaes peras eu vendo"), capaz de ir-se contra a prática escarninha da época expressa no discurso difamador e masculino, conhecido por sua dimensão moralista, censora e misógina (FONSECA, 2011), em que pese sua importante perspectiva lúdica, de jogo cortesão (MONTOYA MARTÍNEZ, 1989; MADERO, 1992; SODRÉ, 2010; 2013).

Embora pudéssemos nos deixar levar pela leitura de uma pretensa posição em certa medida feminista - na esteira do que se deduziu em cantigas de amigo (LEMAIRE, 1987) - a contradizer ou a rebater os preconceitos e a misoginia no cancioneiro satírico afonsino, no que concerne a situações ligadas especialmente a soldadeiras, tal orientação seria inevitavelmente frustrada e equivocada, por 
Linha D'Água (Online), São Paulo, v. 29, n. 1, p. 45-66, jun. 2016

anacrônica. Como se sabe, a voz feminina no universo trovadoresco peninsular, expressa nas cantigas de amigo e nos escárnios de amigo (GUTIERREZ GARCİA), deriva de uma ficção criada pelos trovadores, não obstante a consideração de Rip Cohen de que as cantigas de amigo criadas por mulheres no período pré-trovadoresco chegaram aos jograis e trovadores por meio da oralidade dessas canções femininas tradicionais, que eles imitaram (2003, p. 53, nota 2) não se sabe ao certo em que grau de proximidade. Mesmo a valorização a princípio inequívoca da mulher nas cantigas amorosas cortesãs, Georges Duby (1990) esclareceu a esse respeito que, de fato, a ficção da fin'amors em nada favoreceu a situação das mulheres nobres, ao fim objetos de barganha política e linhagista da Europa medieval. Os homens "esperavam da dama que, depois de ter sido filha dócil, esposa clemente, mãe fecunda, ela fornecesse em sua velhice, pelo fervor de sua piedade e pelo rigor de suas renúncias, algum bafio de santidade à casa que a acolhera" (DUBY, 1997, p. 155). No caso das vilãs, das burguesas, embora elas privassem de menor coerção no comportamento, a expectativa não era diferente.

No que concerne às soldadeiras, pouco se sabe delas senão pelas brevíssimas leis da época e pelo que se insinua no cancioneiro satírico. Acostumadas estas com o ambiente cultural frequentado por trovadores e jograis, é presumível que cultivassem peras capazes de lhes garantirem o respeito mínimo dos parceiros de cantares e de performances. Curiosamente, desconhecem-se cantigas produzidas por essas mulheres, cujos discursos deveriam ser interessantíssimos.

A defesa da mulher, contudo, criada por Afonso $\mathrm{X}$ - se resistirmos à hipótese tentadora de uma recriação do Sábio de um discurso ouvido de uma soldadeira sugere mais uma posição masculina (a crítica zombeteira de um trovador a outro por atacar a mulher indevidamente em sua casa) referente a Ambroa do que propriamente a representação de uma mulher altiva, dona de sua posição enfezada e de suas peras fatais.

No caso do texto literário que propomos para análise, é interessante observar que o acesso é limitado ao discurso masculino, já que são os trovadores que constroem a representação social da mulher, determinando, assim, o que elas dizem, fazem, como se comportam, ou seja, todo juízo de valor é construído sob um ponto de vista masculino e em prol da sociedade da corte ibérica, da elite simbólica.

É fato que a história das mulheres na Idade Média (KLAPISCH-ZUBER, 1993) demonstra essas relações de dominação e poder pautadas na ideologia da época em que se criou uma imagem estereotipada da mulher como ser inferior e corrupto que está sempre predisposto ao pecado (a ira da soldadeira ilustra ainda, aliás, seu orgulho, uma das faltas mais conhecidas da mulher, segundo André $\mathrm{Ca}$ pelão, no terceiro livro de seu Tratado do amor cortês: "O orgulho também costuma 
Linha D'Água (Online), São Paulo, v. 29, n. 1, p. 45-66, jun. 2016

contaminar o sexo feminino: uma mulher impelida pelo impulso do orgulho não consegue segurar a língua nem as mãos, precisa proferir imprecações e cometer crimes" [2000, p. 297]) e sob o domínio do sexo masculino.

O capítulo (XVIII) de um conhecido tratado medieval, Regimiento de los principes, de Egídio Romano (ou Gil de Roma), do século XIII, ilustra igualmente essa visão masculina - frequentemente clerical - da mulher e "demonstra que alguns costumes das mulheres são de louvar e alguns costumes, de censurar". Elas são envergonhadas, piedosas e diligentes, mas são também destemperadas, faladeiras e instáveis. A esta tríade de qualidades e defeitos se acrescenta ainda a falta de sabedoria, o que sujeita as mulheres à custódia dos homens: "Como as mulheres são menos racionais que os homens, por isso devem lhes ser sujeitas. Do mesmo modo, alguns homens que são menos racionais que mulheres devem ser naturalmente servos e submissos" (ROMANO, 1494, Cap. XVIII, f. cxl), e afasta-as, por conseguinte, da ação de aconselhar ("as mulheres não são boas conselheiras porque carecem de entendimento" (1494, Cap. XVIII, f. xcviiij-c. Tradução nossa).

É importante ressaltar que nessas relações de poder, expressas nos diversos discursos literários e didáticos, em que a voz é majoritariamente masculina, ocorreu o abuso, a reprodução ilegítima de conceitos e de valores como forma de interação, comunicação ou outra prática social que serviu e serve apenas ao interesse de uma parte ou de um grupo e são contra os interesses ou da maioria ou de grupos submetidos social, política, religiosa, econômica e culturalmente. Van Dijk (2010, p. 238) esclarece que essas relações de poder pautadas na dominação/subordinação têm sido chamadas de hegemonia.

É nesse sentido que podemos lançar um olhar para as peras da soldadeira numa perspectiva analítica crítica, buscando entender como ocorre o processo individual e cognitivo de interação por meio da linguagem. Pelo viés da análise crítica, entendemos que o discurso da cantiga em análise foi construído a partir da estratégia de polarização do masculino dominador (machista) em relação ao grupo feminino dominado. Observamos que a voz masculina, pertencente ao grupo dominador, não narra a história de uma mulher corajosa, que defende a sua honra, mas utiliza um disclaimers de inversão na tentativa de culpar a vítima, a mulher. Observemos isto nos versos: "Pero d'Ambroa, que o non matasse, / nen fosse contra el desmesurada". Essa estratégia materializa dentro do discurso as estratégias globais de autoapresentação positiva (conciliador e comedido) e outroapresentação negativa (orgulhosa e irascível). Esse recurso subjaz a toda a cantiga em que a representação social da soldadeira é construída no sentido de torná-la destempera$d a$, culpada, pois além de pressupostamente prostituta ainda é ressentida, perigosa e incapaz de perdoar, pois ameaçou Ambroa de morte. 
Linha D'Água (Online), São Paulo, v. 29, n. 1, p. 45-66, jun. 2016

Embora possamos observar em alguns versos a negação da imagem da mulher soldadeira prostituta e uma possível exaltação da sua coragem, essa recusa é aparente, pois a construção da representação social negativa da mulher ocorre justamente no fato de essa mulher - talvez Maria Peres - defender-se de um ataque a sua honra. Noutros termos, trata-se de uma prostituta tentando se defender com o indefensável nesse tipo social imoral, a honra, outro aspecto importante na construção da sátira afonsina, se considerarmos a hipótese de que a voz pode ser a de uma soldadeira: o absurdo de uma mulher querer defender o que não tem. Isso pode ser visto nos versos: " $\mathrm{E}$, se m' eu quisesse seer viltada, / ben acharia quen xe me viltasse; / mais, se m' eu taes non escarmentasse, / cedo meu preito non seeria nada". Assim, a voz da mulher defensiva e ameaçadora, que é bastante marcada no refrão ("se ũa vez assanhar me fazedes, / saberedes quaes peras eu vendo"), remete exatamente para o fato de ela ter sido ofendida socialmente. Esse disclaimers de negação aparente remete ao pensamento: não temos nada contra a soldadeira, redimimo-nos da afronta.

O disclaimers de inversão pode ser observado também na terceira estrofe, quando a soldadeira novamente é apresentada como alguém impiedosa com os que o caluniam: "E, se m' eu quisesse seer viltada, / ben acharia quen xe me viltasse; / mais, se m' eu taes non escarmentasse, /cedo meu preito non seeria nada”.

Os disclaimers de negação aparente e inversão validam autoapresentação positiva do homem e outroapresentação negativa da mulher no discurso da cantiga, e assim deixam transparecer a ideologia sexista que subjaz a toda a cantiga peninsular. Assim, de acordo com as lexias presentes na cantiga, observamos sistematicamente como se dão as estratégias globais de autoapresentação positiva e outroapresentação negativa a partir do quadrado ideológico que consiste em enfatizar aspectos positivos sobre Nós, neste caso, os homens (o trovador e Ambroa) e enfatizar aspectos negativos sobre Eles, neste caso as mulheres soldadeiras (presumivelmente Maria Peres). No quadro abaixo destacamos as lexias que implicam o discurso da polarização com a autoapresentação positiva do trovador e outroapresentação negativa da soldadeira na cantiga: 
Linha D'Água (Online), São Paulo, v. 29, n. 1, p. 45-66, jun. 2016

\begin{tabular}{ccc}
\hline AUTOAPRESENTAÇÃO POSITIVA & \multicolumn{2}{c}{ OUTROAPRESENTAÇÃO NEGATIVA } \\
DO TROVADOR & \multicolumn{2}{c}{ DA SOLDADEIRA } \\
\hline rogava & matasse & escarmentasse, \\
perdoasse & desmesurada & morrer' \\
& assanhar & ardendo \\
& peras & nomeada, \\
& desguisada, & castigasse, \\
& outrogasse, & temuda \\
& deostasse, & dultada \\
\hline
\end{tabular}

Quadro 2: polarização discursiva da cantiga.

Ao lançar um olhar sobre o texto, o leitor não o faz de maneira isolada do mundo e da história que o configuraram, ao contrário, a leitura é conduzida por um indivíduo constituído socialmente que a realizará num processo cognitivo individual ligado às ideologias do grupo ao qual pertence. É importante refletir que as práticas de escrita e de leitura estão permeadas pelas ideologias dos indivíduos que compartilham mais ou menos das mesmas crenças básicas de um determinado grupo. Assim, entre os membros de um mesmo grupo é possível observar atitudes semelhantes, lexias, comportamentos análogos, entre outros. Dessa visão que busca o contexto a partir de um movimento de leitura microestrutural e macroestrutural é que podemos pensar na prática de leitura crítica.

\section{Considerações finais}

O diálogo entre áreas a partir de um aporte teórico multidisciplinar fornece modos sistemáticos de operar abordagens de textos em geral, inclusive os literários, nos quais é possível perceber, como vimos, as relações de poder e as ideologias que as apoiam, como ilustra a cantiga satírica galego-portuguesa, cujo teor muitas vezes lúdico e obsceno procura justamente orientar os cortesãos e demais expectadores do espetáculo trovadoresco a um comportamento exemplar, isto é, ocidental, cristão, heterossexual, masculinista, cortês.

Resgatar o conhecimento que se produziu em relação às mulheres, seja em qualquer época, é uma forma de dar visibilidade e identidade àquela que foi representada pelo olhar do outro, o olhar masculino, a partir de uma perspectiva androcêntrica, patriarcal e clerical da sociedade. A recuperação da memória feminina pela leitura interpretativa e crítica da cantiga medieval não é, para nós, uma tentativa de enfatizar a vitimização da mulher nesse período da história, mas primar pelo reconhecimento de que "as práticas literárias constroem e refletem as imagens e os papeis sociais de uma dada época”(TOMAZI; SODRÉ, 2015, p. 24). 
Linha D'Água (Online), São Paulo, v. 29, n. 1, p. 45-66, jun. 2016

Como demonstramos na análise da cantiga, estudar o passado literário não é simplesmente resgatar a visão ficcional de uma dada época, mas também demonstrar como os valores sociais de homens e mulheres em uma determinada época e lugar de nossa história, podem ser repensados, atualizados e discutidos para explicar as relações de gênero e a visão ainda androcêntrica, patriarcal e clerical em nossa sociedade e, ao mesmo tempo, reconhecer que a memória da figura feminina engajada e livre é permeada por lutas sociais e movimentos de resistência, também na literatura - e aqui vale mencionar a posição avançada de defesa da mulher de Christine de Pisan, no século XIV -, já que a voz da mulher foi imposta pelo olhar masculino e também pela mão escritora masculina.

Diante dessas reflexões, esperamos que esse resgate da memória feminina na poesia medieval possa se constituir em uma maneira de despertar um interesse maior pelo papel da mulher ao longo da história e o ensino da cantiga da literatura medieval possa se tornar um exercício de compreensão de nossas raízes de dominação masculina e de relações hierarquizadas de poder sobre questões de gênero. Identificar marcas desse discurso é resgatar as vozes das minorias silenciadas no ensino da literatura. No caso da literatura da Idade Média é comum observarmos um ensino também silenciado, que não vai além do registro traçado exclusivamente por documentos de autoria masculina, os quais apenas reforçam a condição de inferioridade em que a mulher se encontrava em relação ao papel e ao lugar social ocupado pelo homem na sociedade, ou seja, apenas dão suporte às relações hierárquicas de gênero, de dominação e de poder que ainda prevalecem em muitas relações de gênero na atualidade.

\section{Referências}

ALVAR, Carlos. María Pérez, Balteira. Archivo de Filología Aragonesa, v. XXXVI-XXXVII, p. 11-40, 1985.

BAYNHAM, Mike. Literacy Practices: Investigating Literacy in Social Contexts. London: Longman, 1995.

BAKHTIN, Mikhail. Marxismo e fllosofia da linguagem. São Paulo: Hucitec, 1999.

CABAÑAS, María Dolores. La imagen de la mujer en la Baja Edad Media castellana a traves de las ordenanzas municipales de Cuenca. In: SEGURA GRAIÑO, Cristina (Ed.). Las mujeres en las ciudades medievales: Actas de las III Jornadas de Investigación Interdisciplinaria. Madrid: Seminario de Estudios de la Mujer, 1984. p. 103-108. 
Linha D'Água (Online), São Paulo, v. 29, n. 1, p. 45-66, jun. 2016

CAPELÃO, André. Livro III. Da condenação do amor. In: . Tratado do amor cortês. Trad. Ivone C. Benedetti. São Paulo: Martins Fontes, 2000. p. 265-306.

CASTELLS, Manuel. O poder da identidade. Trad. Dlauss Brandini Gerhardt. 5. ed. São Paulo: Paz e Terra, 2006.

COHEN, Rip. (ed.). 500 cantigas d'amigo. Porto: Campo das Letras, 2003.

CORRAL DÍAZ, Esther. As mulleres nas cantigas medievais. 2. ed. Sada: Castro, 1996.

DIAS, Tatiana Rosa Nogueira. Identidade e violência contra mulher: uma análise de discurso crítica. In: SATO, Denise Tamaé Borges.; BATISTA JUNIOR, José Ribamar Lopes. (Org.). Contribuições da análise de discurso crítica no Brasil: uma homenagem à Izabel Magalhães. Campinas: Pontes, 2013. p. 119-145.

DUBY, Georges. O modelo cortês. In: KLAPISCH-ZÜBER, Christiane. (Dir.). História das mulheres: a Idade Média. Trad. Ana Losa Ramalho (et al). Porto: Afrontamento, 1990.p.331-351.

Damas do século XII: a lembrança das ancestrais. Trad. Maria Lúcia Machado. São Paulo: Companhia das Letras, 1997.

FILIOS, Denise. K. Jokes on Soldadeiras in the Cantigas de Escarnho e de Mal Dizer. La Corónica, Williamsburg, v. 26, n. 2, p. 29-39, 1998.

FONSECA, Pedro Carlos Louzada. Fontes literárias da difamação e da defesa da mulher na Idade Média: Referências obrigatórias. In: MASSINI-CAGLIARI, Gladis et al. (Org.). Série Estudos Medievais 2, Araraquara. Disponível em:

http://portal.fclar.unesp.br/poslinpor/gtmedieval/publicacoes/serie02_fontes/fontes_pedro -louzada.pdf. Acesso em: 20 fev. 2016.

GRAMSCI, Antonio. Prison notebooks. New York: International, 1971.

HEBERLE, Viviane Maria; MEURER, José Luiz. Reading in English as a Foreign Language. In: CAMPOS, J. (Ed.). Educação para crescer: projeto melhoria da qualidade de ensino. Porto Alegre: Secretaria da Educação do Governo do Estado do Rio Grande do Sul, 1993. p. 41-58.

. Critical Reading: Integrating Principles of Critical Discourse Analysis and Gender Studies. Ilha do Desterro, Florianópolis, n. 38, p. 115-138, 2000.

KLAPISCH-ZUBER, Christiane. (Dir.). História das mulheres no Ocidente: Idade Média. Trad. Ana Rosa Ramalho et al. Porto: Afrontamento, 1993. v. 2.

TOMAZI, M. M.; SODRÉ, P. R. A cantiga medieval como memória histórica da construção 
Linha D'Água (Online), São Paulo, v. 29, n. 1, p. 45-66, jun. 2016

LANZ, Eukene Lacarra. Sobre la sexualidad de las soldaderas en las cantigas d'escarnho e de maldizer. In: (Dir. y Ed.). Amor, escarnio y linaje en la literatura gallego-portuguesa. Zarautz: Universidad del País Vasco, [2002]. p. 75-97.

LAPA, Manuel Rodrigues. (Ed.). Cantigas d'escarnho e de maldizer dos cancioneiros medievais galego-portugueses. 3. ed. ilustrada. Lisboa: João Sá da Costa, 1995.

LEMAIRE, Raymond. Le discours de la cantiga de amigo. In: Passions et positions: contribuition à une sémiotique du sujet dans la poésie lyrique médiévale en langues romanes. Amsterdam: Rodopi, 1987.p. 81-184.

LIU, Benjamin. Medieval Joke Poetry: the cantigas d'escarnho e de mal dizer. Cambridge (Massachusetts): Harvard University, 2004.

LIVRO das leis e posturas. Leitura paleográfica e transcrição de Maria Teresa Campos Rodrigues. Lisboa: Universidade de Lisboa, 1971.

LOPES, G. V. (Org.). Cantigas medievais galego-portuguesas. Disponível em:

http://www.cantigas.fcsh.unl.pt/ cantiga.asp?cdcant=497\&pv=sim. Acesso em: 20 fev. 2016.

LOPES, Maria da Graça Videira. A sátira nos cancioneiros medievais galego-portugueses. 2. ed. Lisboa, Estampa, 1998.

MADERO, Marta. Manos violentas, palabras vedadas: la injuria en Castilla y León (siglos XIII-XV). Madrid: Taurus, 1992.

MEURER, José Luiz. O trabalho de leitura crítica: recompondo representações, relações e identidades sociais. Ilha do Desterro, Florianópolis, n. 38, p. 155-171, 2000.

MONTOYA MARTÍNEZ, Jesús. Caracter lúdico de la literatura medieval (A propósito del 'jugar de palabra'. Partida Segunda, tít. IX, ley XXIX). In: CASTILLO, C. Argente del et al. (Rec.). Homenaje al Profesor Antonio Gallego Morell. Granada: Universidad de Granada, 1989. p. 413-442.

OLIVEIRA, Luciano Amaral. Possíveis contribuições da análise crítica do discurso para o ensino de português. Revista Linguas e Letras, v. 13, n. 24, p. 143-160, 2012.

ORDENAÇÕES afonsinas. Edição fac-similada da edição da Real Imprensa da Universidade de Coimbra, de 1792. Lisboa: Fundação Calouste Gulbenkian, 1984.

PAREDES, Juan (Ed.). El cancionero profano de Alfonso X el Sabio. Santiago de Compostela: Universidade de Santiago de Compostela, 2010.

ROMANO, Egidio. Regimiento de los principes. Trad. de Juan Garcia de Castrojeriz. Sevilla: Meinardo Ungut/Estanislao Polono, 1494.

TOMAZI, M. M.; SODRÉ, P. R. A cantiga medieval como memória histórica da construção 
Linha D'Água (Online), São Paulo, v. 29, n. 1, p. 45-66, jun. 2016

SCHMITT, Jean-Claude. A história dos marginais. In: LE GOFF, Jacques et al. A história nova. São Paulo: Martins Fontes, 1998. p. 261-289.

SODRÉ, Paulo Roberto. O riso no jogo e o jogo do riso na sátira galego-portuguesa. Vitória: Edufes, 2010.

. O nome de donas e soldadeiras nas cantigas satíricas de Afonso X. Convergência Lusíada, Rio de Janeiro, n. 27, p. 83-102, jan./jun. 2012.

.Em nome do riso: os trovadores galego-portugueses e a sátira em jogo. Revista Signum, Brasília, v. 14, n. 3, p. 18-39, 2013. Disponível em: http://www.abrem.org.br/ revistasignum/ index.php/revistasignumn11/article/viewFile/109/102. Acesso em: 20 fev. 2016.

TOMAZI, Michelini Mattedi; SODRÉ, Paulo Roberto. Imagens de atores sociais, papeis e identidades na poesia de Maria Antonieta Tatagiba. In: NASCIMENTO, Jarbas Vargas; TOMAZI, Michelini Mattedi; SODRÉ, Paulo Roberto. Lingua, Literatura e Ensino. São Paulo: Blucher, 2015.p. 23-35.

VAN DIJK, Teun Adrianus. Ideology: a Multidisciplinary Approach. London: Sage, 1998.

Critical Discourse Analysis. In: SCHIFFRIN, Deborah; TANNEN, Deborah; HAMILTON, Heidi E. (Ed.). The Handbook of Discourse Analysis. Hong Kong: Blackwell, 2001a. p. 352-371.

Algunos principios de una teoría del contexto. ALED. Revista Latinoamericana de Estudios del Discurso, Venezuela, v. 1, n. 1, p. 69-81, 2001 b.

. Discurso e poder. Organização e tradução Judith Hoffnagel e Karina Falcone. 2. ed. São Paulo: Contexto, 2010.

Discurso e contexto: uma abordagem sociocognitiva. Tradução Rodolfo Ilari. São Paulo: Contexto, 2012.

VASCONCELOS, Carolina Michaelis de. Glosas marginais ao cancioneiro medieval português. Tradução de Yara Frateschi Vieira et al. Coimbra: Universidade de Coimbra, 2004.

ZAREMSKA, Hanna. Marginais. In: LE GOFF, Jacques; SCHMITT, Jean-Claude (Coord.). Dicionário temático do Ocidente medieval. Tradução organizada por Hilario Franco Jr. São Paulo: Universidade do Sagrado Coração, 2002. 2 v. v. II, p. 121-136. 